\title{
Interaction between Inhaled Nitric Oxide and Intravenous Sildenafil in a Porcine Model of Meconium Aspiration Syndrome
}

\author{
LARA S. SHEKERDEMIAN, HANNE B. RAVN, AND DANIEL J. PENNY \\ Paediatric Intensive Care Unit [L.S.S.], Royal Children's Hospital, Parkville, Victoria 3052, Australia; \\ Department of Anaesthesia and Intensive Care \& Institute of Experimental Clinical Research [H.B.R.], \\ Aarhus University Hospital, 8200-Aarhus, Denmark; and Cardiology Department [D.J.P.], Royal \\ Children's Hospital, Parkville, Victoria 3052, Australia
}

\begin{abstract}
There has been recent interest in the use of the phosphodiesterase-5 inhibitor sildenafil for treating pulmonary hypertension. We examined the interaction between inhaled nitric oxide (iNO) and i.v. sildenafil in 12 piglets with acute pulmonary hypertension and lung injury secondary to meconium aspiration. Six animals (controls) received no intervention after meconium instillation, and six received iNO (20 ppm) from $120 \mathrm{~min}$, with the addition at $240 \mathrm{~min}$ of an i.v. sildenafil infusion ( $2 \mathrm{mg} / \mathrm{kg}$ over $2 \mathrm{~h}$ ). Meconium instillation increased mean pulmonary artery $(\mathrm{PA})$ pressure from $16.0 \pm 3.1$ to $24.8 \pm 4.6 \mathrm{~mm} \mathrm{Hg}(p<0.01)$ and pulmonary vascular resistance (PVR) from $0.047 \pm 0.008$ to $0.089 \pm 0.027 \mathrm{~mm} \mathrm{Hg} \cdot \mathrm{ml}^{-1} \cdot \mathrm{min}^{-1}$ $\cdot \mathrm{kg}^{-1}(p<0.01)$. Oxygenation index increased from $3 \pm 0.8$ to 8.3 $\pm 3.0(p<0.01)$. There were no further changes beyond $120 \mathrm{~min}$ in controls. iNO reduced PA pressure and PVR to baseline values, without influencing oxygenation. The addition of sildenafil further reduced PA pressure, tended to increase the cardiac output, and reduced PVR from $0.049 \pm 0.02$ to $0.028 \pm 0.01 \mathrm{~mm} \mathrm{Hg} \cdot \mathrm{ml}^{-1}$. $\min ^{-1} \cdot \mathrm{kg}^{-1}(p<0.05)$. Sildenafil lowered the systemic blood pressure and systemic vascular resistance and produced profound arterial hypoxemia, reducing arterial $\mathrm{PO}_{2}$ from $69 \pm 23 \mathrm{~mm} \mathrm{Hg}$ to
\end{abstract}

\section{ABSTRACT}

$49 \pm 15 \mathrm{~mm} \mathrm{Hg}$, despite substantial increases first in inspired oxygen fraction and subsequently in mean airway pressures. Consequently, the oxygenation index increased by $13.9 \pm 4.8(p=$ 0.01 ). When given in addition to iNO, sildenafil at a dose of $>0.5$ $\mathrm{mg} / \mathrm{kg}$ produced profound pulmonary vasodilation, but this was coupled with an unacceptable deterioration in oxygenation and systemic vasodilation in this model of pulmonary hypertension with acute parenchymal lung disease. (Pediatr Res 55: 413-418, 2004)
Abbreviations
SVR, systemic vascular resistance
PVR, pulmonary vascular resistance
$\mathrm{F}_{\mathbf{H}}{ }_{2}$, inspired oxygen fraction
CVP, central venous pressure
PAP, mean pulmonary artery pressure
PCWP, mean pulmonary capillary wedge pressure
OI, oxygenation index
iNO, inhaled nitric oxide
$\mathbf{P}_{\mathbf{A W}}$, airway pressure

The discovery of the nitric oxide pathway has revolutionized the treatment of acute pulmonary hypertension. Inhaled nitric oxide (iNO) produces pulmonary vasodilation in ventilated lung regions by increasing cGMP levels within vascular smooth muscle (1) and is used to treat pulmonary hypertension in a variety of conditions, including persistent pulmonary hypertension of the newborn (2), primary pulmonary hypertension (3), and pulmonary hypertension early after pediatric cardiac surgery (4).

Received November 25, 2002; accepted July 17, 2003.

Correspondience: Lara Shekerdemian, M.D., Paediatric Intensive Care Unit, Royal Children's Hospital, Flemington Road, Parkville, Victoria 3052, Australia; e-mail: lara.shekerdemian@rch.org.au

This research was supported with a grant from The University of Aarhus, Denmark.

DOI: 10.1203/01.PDR.0000112033.81970.C2
Agents that inhibit the endogenous breakdown of cGMP by phosphodiesterase-5 in the lungs could theoretically have a role as adjuncts or alternatives to iNO in the treatment of acute pulmonary hypertension. E4021, a selective phosphodiesterase-5 inhibitor, was recently shown to produce highly selective pulmonary vasodilation in a model of neonatal pulmonary hypertension without parenchymal lung disease, and the authors concluded that this class of drugs may have a role in the clinical setting (5).

There are increasing numbers of reports of the use of sildenafil, another phosphodiesterase-5 inhibitor, in the treatment of pulmonary hypertension. Oral sildenafil inhibits hypoxia-induced chronic pulmonary hypertension in an animal model (6), and there are anecdotal reports of its use in the clinical treatment of primary pulmonary hypertension in adults and children $(7,8)$.

Effective combined therapy using iNO and oral sildenafil has also been reported in the clinical arena. Anecdotal reports 
suggest "synergy" between the agents in the treatment of pulmonary hypertension with severe parenchymal lung disease and an intracardiac right-to-left shunt (9) and in the prevention of acute (10) and rebound (11) pulmonary hypertension in patients after surgery for congenital heart disease.

Meconium aspiration results in acute parenchymal lung disease and pulmonary vasoconstriction, which together give rise to a vicious cycle of intrapulmonary and, when present, intracardiac right-to-left shunting resulting in hypoxic respiratory failure. We recently demonstrated that i.v. sildenafil produces equivalent pulmonary vasodilation to $\mathrm{iNO}$ when given alone in a piglet model of meconium aspiration syndrome (12). The purpose of our current study was to evaluate the combined influences of iNO and i.v. sildenafil on pulmonary and systemic hemodynamics and oxygenation in this model.

\section{METHODS}

Experimental preparation. The study was approved by the Institutional Review Board for the care of animal subjects, and conformed to the Guide for the Care and Use of Laboratory Animals published by the US National Institutes of Health (National Institutes of Health Publication No 85-23, revised 1996). Twelve Danish Landrace piglets that weighed $5.2 \pm 0.4$ $\mathrm{kg}$ were premedicated with intramuscular ketamine $(10 \mathrm{mg} / \mathrm{kg})$ and midazolam $(0.5 \mathrm{mg} / \mathrm{kg})$, followed by i.v. ketamine $(5$ $\mathrm{mg} / \mathrm{kg}$ ). The animals were intubated with cuffed endotracheal tubes and ventilated (Servo ventilator 900D; Siemens, Solna, Sweden). The initial ventilator settings were preset to deliver a minute volume of $300 \mathrm{~mL} / \mathrm{kg}$, a rate of 30 breaths $/ \mathrm{min}$, a positive end-expiratory pressure of $4-5 \mathrm{cmH}_{2} \mathrm{O}$, and an inspired oxygen fraction $\left(\mathrm{FIO}_{2}\right)$ of 0.25 . A stable plane of anesthesia was maintained with i.v. infusions of fentanyl (30-50 $\left.\mu \mathrm{g} \cdot \mathrm{kg}^{-1} \cdot \mathrm{h}^{-1}\right)$ and midazolam $\left(2-5 \mathrm{mg} \cdot \mathrm{kg}^{-1} \cdot \mathrm{h}^{-1}\right)$. Valved introducers (William Cook, Bjaerverskov, Denmark) were advanced through a cutdown incision from the right internal carotid artery to the brachiocephalic artery for systemic blood pressure measurement and blood sampling, and from the right external jugular vein to the superior caval vein for measurement of central venous pressure (CVP). A 5-F thermodilution catheter (Baxter, Irvine, CA, U.S.A.) was passed under fluoroscopic guidance through a sheath placed in the left external jugular vein to the origin of the left pulmonary artery and was used for measurement of pulmonary artery pressure (PAP), pulmonary capillary wedge pressure (PCWP), and cardiac output.

Experimental protocol. Heart rate, systemic blood pressure, PAP, and CVP were continuously monitored (Sirecust; Siemens). After the preparation was completed, an arterial blood sample was taken for blood gas analysis. The $\mathrm{FIO}_{2}$ and tidal volumes were adjusted to maintain an arterial $\mathrm{PO}_{2}$ of $70-100$ $\mathrm{mm} \mathrm{Hg}$ and carbon dioxide of 35-45 mm Hg. After $30 \mathrm{~min}$, hemodynamic data and ventilatory settings were recorded, cardiac output was measured in triplicate by thermodilution, and blood gas analysis was performed. This set of measurements was taken as baseline ( $0 \mathrm{~min})$.

After baseline measurements, each subject received a deep intratracheal instillation $(3 \mathrm{~mL} / \mathrm{kg}$ ) of a $20 \%$ solution of pooled human meconium. First-pass human meconium was obtained and stored at $-20^{\circ} \mathrm{C}$. Before commencing the studies, meconium was thawed at room temperature and diluted with $0.9 \%$ saline to make a $20 \%$ solution; the resulting mixture was filtered to remove large particulate matter.

The piglets were randomly assigned to one of two groups, and the total study period was $360 \mathrm{~min}$ for both groups. Six controls received no further interventions other than ventilatory adjustments according to blood gases, and the remaining six received iNO (20 ppm) starting $120 \mathrm{~min}$ after meconium instillation, with the addition of an infusion of i.v. sildenafil (2 $\mathrm{mg} / \mathrm{kg}$ over $2 \mathrm{~h}$; Pfizer, Sandwich, UK) at $240 \mathrm{~min}$. An additional arterial blood gas was taken $30 \mathrm{~min}$ after each intervention (meconium, nitric oxide, sildenafil), and ventilation was adjusted accordingly. A full set of hemodynamic measurements, blood gases, and ventilatory settings were recorded every $60 \mathrm{~min}$ in all subjects. After the final set of recordings (360 $\mathrm{min}$ ), a 10-mL injection of radio-opaque contrast was given into the right atrium under fluoroscopic imaging to exclude any intracardiac or transductal shunt. After this, the subjects were killed with an overdose of pentobarbital.

Physiologic calculations:

SVR $\left(\mathrm{mm} \mathrm{Hg} / \mathrm{mL} \cdot \min -1 \cdot \mathrm{kg}^{-1}\right)=$ (mean systemic arterial pressure $-\mathrm{CVP}) /$ cardiac output

Pulmonary vascular resistance $(\mathrm{PVR})(\mathrm{mm} \mathrm{Hg} / \mathrm{mL} \cdot \mathrm{min}-1$ $\left.\cdot \mathrm{kg}^{-1}\right)=(\mathrm{PAP}-\mathrm{PCWP}) /$ cardiac output

$$
\mathrm{OI}=\mathrm{P}_{\mathrm{AW}}\left(\mathrm{cmH}_{2} \mathrm{O}\right) * \mathrm{FIO}_{2} * 100 / \text { arterial } \mathrm{Po}_{2}(\mathrm{~mm} \mathrm{Hg})
$$

\section{Statistical analysis}

Statistical analysis was performed using Sigmastat for Windows (SPSS Science, Chicago, IL, U.S.A.). Within-group data were compared using an ANOVA for repeated measures, using the Bonferroni method for post hoc analysis of significant differences; between-group data at specific time points were compared using Mann-Whitney rank sum test. All results are expressed as mean $\pm \mathrm{SD} ; p<0.05$ was considered statistically significant.

\section{RESULTS}

Effect of meconium instillation (0-120 min). The baseline recordings and initial changes in hemodynamics and ventilatory variables after meconium instillation were similar for both groups. Therefore, the initial responses to meconium instillation for all 12 animals are considered together in Table 1. Meconium instillation produced an acute increase in mean PAP $(p<0.001)$. Mean aortic pressures, PCWPs, and CVPs were unchanged, whereas cardiac output tended to increase $(p=$ $0.07)$. As a result, PVR increased significantly $(p<0.001)$, with a mean increase of $112 \%$. Systemic vascular resistance (SVR) was unchanged, and the PVR-to-SVR ratio increased $(p<0.001)$ : a mean increase of $120 \%$.

Ventilatory changes after meconium instillation are given in Table 1. Mean airway pressure $\left(\mathrm{P}_{\mathrm{AW}}\right)$ and $\mathrm{FiO}_{2}$ were increased, despite that there was a significant fall in arterial oxygen tension. Thus, the oxygenation index (OI) more than doubled after meconium instillation. All of the above statistically significant changes occurring during the first 120 min resulted 
Table 1. Hemodynamic and ventilatory data at baseline (0 min), $60 \mathrm{~min}$, and $120 \mathrm{~min}$ after instillation of meconium for the group as a whole $(n=12)$

\begin{tabular}{|c|c|c|c|}
\hline & $0 \mathrm{~min}$ & $60 \mathrm{~min}$ & $120 \mathrm{~min}$ \\
\hline Mean PA pressure (mm $\mathrm{Hg})$ & $16(3.1)$ & $22(4.6)$ & $25(4.6) *$ \\
\hline Mean aortic pressure (mm $\mathrm{Hg})$ & $65(11)$ & $66(11)$ & $66(9)$ \\
\hline PCWP (mm Hg) & $7(2.5)$ & $7(3.1)$ & $7(3.0)$ \\
\hline Cardiac output $\left(\mathrm{mL} \cdot \min ^{-1} \cdot \mathrm{kg}^{-1}\right)$ & $187(35)$ & $218(40)$ & $210(44)$ \\
\hline $\operatorname{PVR}\left(\mathrm{mm} \mathrm{Hg} \cdot \mathrm{mL}^{-1} \cdot \min ^{-1} \cdot \mathrm{kg}^{-1}\right)$ & $0.04(0.009)$ & $0.08(0.018)$ & $0.09(0.020)^{*}$ \\
\hline $\operatorname{SVR}\left(\mathrm{mm} \mathrm{Hg} \cdot \mathrm{mL}^{-1} \cdot \min ^{-1} \cdot \mathrm{kg}^{-1}\right)$ & $0.33(0.15)$ & $0.29(0.07)$ & $0.31(0.06)$ \\
\hline $\mathrm{PaCO}_{2}(\mathrm{~mm} \mathrm{Hg})$ & $38(5)$ & $41(6)$ & $41(5)$ \\
\hline Mean airway pressure $\left(\mathrm{cmH}_{2} \mathrm{O}\right)$ & $9(1.5)$ & $13(2.5)$ & $14(2.6)^{*}$ \\
\hline Inspired oxygen $(\%)$ & $33(5)$ & $39(6)$ & $41(7)^{*}$ \\
\hline OI & $3.2(0.8)$ & $8.8(2.6)$ & $8.9(2.9)^{*}$ \\
\hline
\end{tabular}

Data are presented as mean (SD).

$* P<0.05$ vs baseline.

from an acute effect of meconium between 0 and $60 \mathrm{~min}$, which was subsequently sustained between 60 and $120 \mathrm{~min}$.

Changes in hemodynamics between 120 and $360 \mathrm{~min}$. In the controls, there were no significant changes in any of the hemodynamic variables over the remainder of the study period (Fig. 1, Table 2).

In the animals that were given iNO between 120 and 240 min, the mean PAP fell by $7.5 \pm 4.5 \mathrm{~mm} \mathrm{Hg}(p<0.01)$, whereas mean aortic pressure tended to increase $(p=0.055)$. The mean PCWP, CVP, and cardiac output were unchanged. Nitric oxide reduced the PVR by $28 \%(0.036 \pm 0.024 \mathrm{~mm} \mathrm{Hg}$ $\left.\cdot \mathrm{ml}^{-1} \cdot \min ^{-1} \cdot \mathrm{kg}^{-1} ; p<0.05\right)$, without changing the SVR, and thus the PVR-to-SVR ratio fell significantly $(p<0.05)$. Administration of i.v. sildenafil to these animals between 240 and 360 min further reduced mean PAP by $27 \%$ (an additional $3.2 \pm 2.6 \mathrm{~mm} \mathrm{Hg} ; p<0.05$ ) and reduced aortic pressure by $13.8 \pm 8.7 \mathrm{~mm} \mathrm{Hg}(p<0.05)$. Mean PCWP and CVP were unchanged, whereas cardiac output tended to increase $(p=$ 0.06). Intravenous sildenafil produced a further fall in PVR of $0.026 \pm 0.019 \mathrm{~mm} \mathrm{Hg} \cdot \mathrm{ml}^{-1} \cdot \mathrm{min}^{-1} \cdot \mathrm{kg}^{-1}(p<0.05)$. However, SVR fell by $0.104 \pm 0.08 \mathrm{~mm} \mathrm{Hg} \cdot \mathrm{ml}^{-1} \cdot \mathrm{min}^{-1}$. $\mathrm{kg}^{-1}(p<0.001)$; thus, there was no significant change in the PVR-to-SVR ratio. Of note, all of the hemodynamic changes during i.v. sildenafil infusion were already statistically significant at $300 \mathrm{~min}$.

Changes in gas exchange between 120 and 360 min. In the controls, there were no further changes in gas exchange during this part of the study. In the treatment group, ventilatory parameters and OI were unchanged during nitric oxide inhalation between 120 and $240 \mathrm{~min}$. However, the addition of sildenafil between 240 and 360 min resulted in major changes in gas exchange and ventilatory requirements. Arterial blood gases as taken at $270 \mathrm{~min}$ (30 min after commencing sildenafil) showed hypoxia, with arterial oxygen tension falling by $22 \pm$ $14 \mathrm{~mm} \mathrm{Hg}(28 \pm 13 \% ; p<0.05)$. In response to the blood gases at $270 \mathrm{~min}$, inspired oxygen concentration was increased (by $25 \pm 13 \%$ ) in all piglets in an attempt to improve oxygenation. Mean $\mathrm{P}_{\mathrm{AW}}$ was not adjusted at this stage, and OI more than doubled by $300 \mathrm{~min}$. Despite a further increase in inspired oxygen in piglets that were not already receiving $100 \%$ oxygen and an increase in mean $\mathrm{P}_{\mathrm{AW}}$ of $3 \pm 1.4 \mathrm{cmH}_{2} \mathrm{O}(p<0.05)$, arterial oxygen tension still fell by $19.3 \pm 11 \mathrm{~mm} \mathrm{Hg}$ between 240 and $360 \mathrm{~min}(p<0.05)$. Consequently, the OI increased by $16 \pm 10$ units $(p<0.05)$ during this period (Fig. 2).

\section{DISCUSSION}

Meconium aspiration is the single most common cause of hypoxemic respiratory failure affecting term neonates. Meconium aspiration acutely results in airway obstruction, acute lung injury, pulmonary hypertension, and intrapulmonary and, where present, intracardiac shunting. iNO is the first-line pulmonary vasodilator in many centers for the treatment of neonatal hypoxemic respiratory failure, but the response can be variable. For example, in meconium aspiration syndrome, it has been suggested that the effective alveolar distribution of iNO may be limited by meconium in the airways and that this may in part account for the variable response that has been described in this group (13). Nitric oxide alone is not always sufficient to break the vicious cycle of hypoxemia and pulmonary hypertension; thus, a percentage of infants continue to require extracorporeal life support, and a minority still die. Furthermore, the use of iNO can bring with it the potential side effects of toxicity and rebound pulmonary hypertension upon its withdrawal. There is a need to explore other agents that produce their pulmonary vasodilator effects through cGMP, as these may complement nitric oxide by augmenting its effects, by allowing a dose reduction or enabling its smooth discontinuation.

We previously demonstrated that the phosphodiesterase- 5 inhibitor i.v. sildenafil, when administered alone, produced a similar degree of pulmonary vasodilation to iNO in a piglet model of acute meconium aspiration syndrome (12). This is a model of acute pulmonary hypertension with acute lung injury, without an intracardiac shunt. The aim of our current study was to evaluate the effect of i.v. sildenafil in the presence of iNO-induced (and, therefore, cGMP-dependent) pulmonary vasodilation on pulmonary and systemic hemodynamics and oxygenation in the same animal model. 


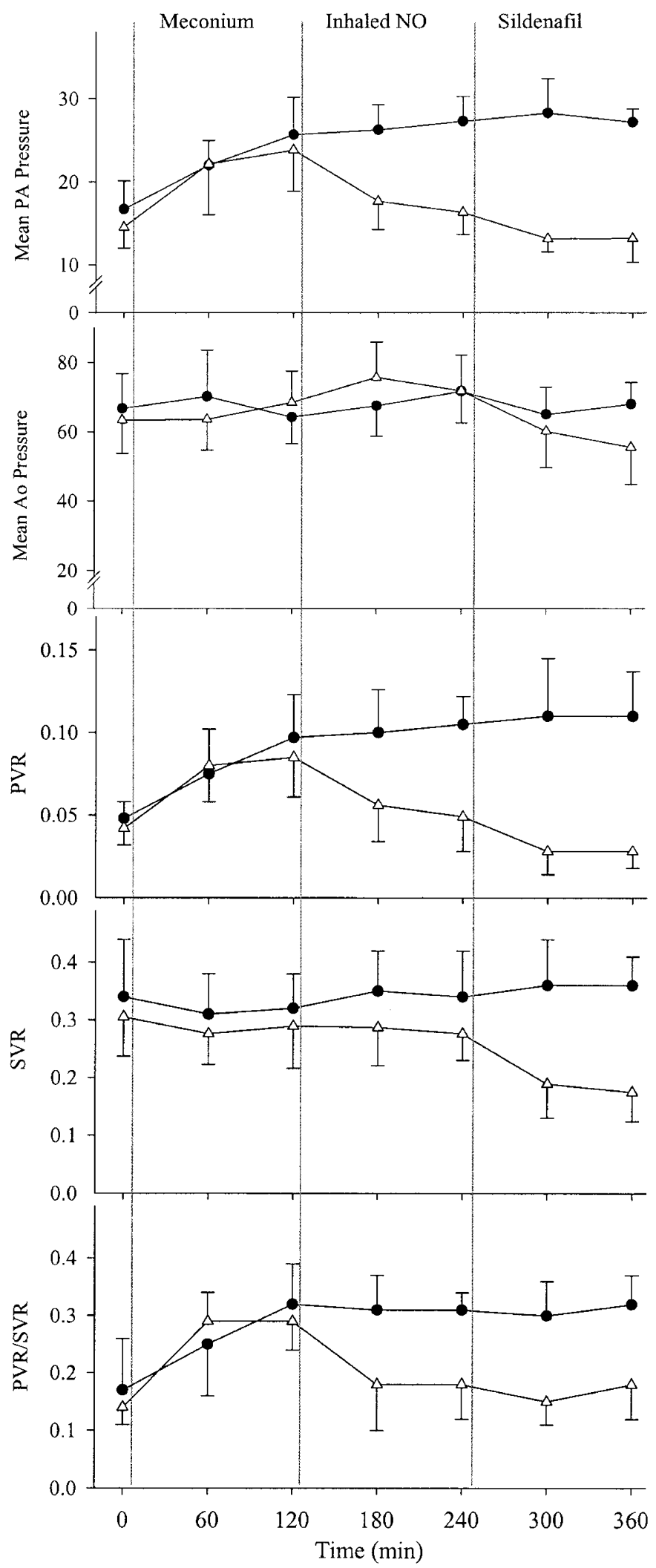

Figure 1. Changes in pulmonary and systemic hemodynamics in controls $(\bullet)$ and test animals $(\triangle)$. Mean values are given; error bars represent SD. Meconium instillation produced pulmonary hypertension in both groups, and this was sustained in controls. The addition of iNO reversed these changes between 120 and $240 \mathrm{~min}$, and the addition of sildenafil further reduced PA pressure and PVR but also produced systemic hypotension and reduced SVR.
In this study, we demonstrated that the addition of sildenafil in animals that were already receiving iNO enhanced the pulmonary vasodilation. However, we believe that this potentially desirable interaction was outweighed by the profound detrimental influences of this combination of agents on arterial oxygenation. Furthermore, i.v. sildenafil resulted in systemic side effects, with arterial hypotension and a fall in SVR.

Previous investigators have shown beneficial interactions between iNO and systemic phosphodiesterase- 5 inhibitors in pulmonary hypertension without acute lung injury. Intravenous zaprinast enhanced the pulmonary vasodilator effect of nitric oxide and improved oxygenation in an in utero duct ligation model (14). Zaprinast and sildenafil both augmented the pulmonary vasodilation produced by nitric oxide in awake animals with pulmonary hypertension induced by the vasoconstrictor U46619 (15).

The interaction between iNO and systemic phosphodiesterase-5 inhibitors in pulmonary hypertension with lung injury has been reported less. Dipyridamole produced a transient improvement in oxygenation and pulmonary hypertension in sick neonates who had congenital diaphragmatic hernia with an intracardiac right-to-left shunt and were already receiving nitric oxide (16). Oral sildenafil reduced the intracardiac rightto-left shunt in a patient who had severe interstitial lung disease and pulmonary hypertension and was receiving nitric oxide (9). However, in an animal model of acute lung injury, zaprinast abolished the beneficial effects of iNO on pulmonary hypertension and oxygenation and actually worsened arterial oxygenation, with an increase in venous admixture (17).

In the current study, i.v. sildenafil augmented the nitric oxide-induced pulmonary vasodilation, producing a further reduction in PAP and an increase in cardiac output compared with controls. However, while producing pulmonary vasodilation, sildenafil had detrimental effects on oxygenation, necessitating a substantial increase in ventilatory settings: first an increase in the $\mathrm{FIO}_{2}$ and subsequently in ventilatory pressures. This resulted in more than doubling of the OI. Indeed, the inspired oxygen concentration was increased to $100 \%$ in three of the subjects by the end of the study period. This magnitude of increase in ventilatory requirements to achieve only borderline oxygenation would be considered unacceptable in the clinical arena.

iNO is highly selective for ventilated lung areas. In some circumstances, for example, in the setting of chronic pulmonary hypertension, systemic pulmonary vasodilators may offer the advantage of more widespread pulmonary vasodilation, especially when this is coupled with an increase in cardiac output. Moreover, in the presence of an intracardiac right-toleft shunt, this may result in less intracardiac shunting and improved oxygenation. However, in acute pulmonary hypertension and lung injury without an intracardiac shunt, the use of systemic agents in addition to iNO may produce more generalized pulmonary vasodilation, redirecting blood away from the selectively dilated (by nitric oxide) ventilated regions to nonventilated areas, thus increasing intrapulmonary shunt and exacerbating arterial hypoxemia. We suggest that this was the mechanism underlying the profound deterioration in oxygenation when sildenafil was given in addition to iNO in our 
Table 2. Hemodynamic and ventilatory data between 120 and 360 min in controls $(n=6)$ and in animals receiving iNO from 120 min with the addition of i.v. sildenafil at $240 \mathrm{~min}(\mathrm{n}=6)$

\begin{tabular}{|c|c|c|c|c|c|c|c|}
\hline & \multicolumn{3}{|c|}{ Controls } & \multicolumn{4}{|c|}{ iNO at $120 \mathrm{~min}$ and sildenafil at $240 \mathrm{~min}$} \\
\hline & $120 \mathrm{~min}$ & $240 \mathrm{~min}$ & $360 \mathrm{~min}$ & $120 \mathrm{~min}$ & $240 \mathrm{~min}$ & $300 \mathrm{~min}$ & $360 \mathrm{~min}$ \\
\hline Mean PA pressure (mm Hg) & $26(3.4)$ & $27(3.1)$ & $27(2.0)$ & $24(5)$ & $16(2.7) * \S$ & $13(1.6) \S \dagger$ & $13(2.9) \S \ddagger$ \\
\hline Mean aortic pressure (mm Hg) & $64(8)$ & $72(9)$ & $68(6)$ & $69(9)$ & $72(10)$ & $60(10) \S \dagger$ & $55(11) \S \ddagger$ \\
\hline PCWP (mm Hg) & $7(1.7)$ & $7(1.9)$ & $7(2.8)$ & $6(3.3)$ & $5(2.3)$ & $6(2.3)$ & $6(3.0)$ \\
\hline CVP (mm Hg) & $8(1.8)$ & $7(1.6)$ & $8(2.3)$ & $6(2.9)$ & $7(1.0)$ & $6(1.0)$ & $7(1.0)$ \\
\hline $\begin{array}{l}\text { Cardiac output } \\
\qquad\left(\mathrm{mL} \cdot \min ^{-1} \cdot \mathrm{kg}^{-1}\right)\end{array}$ & $188(16)$ & $192(32)$ & $169(18)$ & $220(48)$ & $247(39)$ & $314(55) \S$ & $310(68) \S$ \\
\hline $\begin{array}{l}\text { PVR } \\
\qquad\left(\mathrm{mm} \mathrm{Hg} \cdot \mathrm{mL}^{-1} \cdot \mathrm{min}^{-1} \cdot \mathrm{kg}^{-1}\right)\end{array}$ & $0.10(0.026)$ & $0.11(0.017)$ & $0.11(0.027)$ & $0.09(0.024)$ & $0.049(0.021)^{*} \S$ & $0.028(0.014) \S \dagger$ & $0.028(0.010) \S \ddagger$ \\
\hline $\begin{array}{l}\text { SVR } \\
\qquad\left(\mathrm{mm} \mathrm{Hg} \cdot \mathrm{mL}^{-1} \cdot \min ^{-1} \cdot \mathrm{kg}^{-1}\right)\end{array}$ & $0.32(0.06)$ & $0.34(0.08)$ & $0.35(0.05)$ & $0.29(0.07)$ & $0.28(0.05)$ & $0.19(0.06) \S \dagger$ & $0.19(0.05) \S \ddagger$ \\
\hline PVR/SVR & $0.32(0.07)$ & $0.31(0.03)$ & $0.32(0.05)$ & $0.29(0.05)$ & $0.18(0.06)^{*} \S$ & $0.15(0.04) \S$ & $0.18(0.06) \S$ \\
\hline $\mathrm{PaO}_{2}(\mathrm{~mm} \mathrm{Hg})$ & $78(16)$ & $74(23)$ & $76(17)$ & $78(21)$ & $69(20)$ & $50(15) \S \dagger$ & $49(15) \div$ \\
\hline $\mathrm{PaCO}_{2}(\mathrm{~mm} \mathrm{Hg})$ & $41(7.5)$ & $39(7.5)$ & $40(6.0)$ & $41(6.0)$ & $43(9.0)$ & $42(5.0)$ & $47(7.5)$ \\
\hline $\mathrm{P}_{\mathrm{AW}}\left(\mathrm{cmH}_{2} \mathrm{O}\right)$ & $14(3.9)$ & $14.8(3.4)$ & $13.3(3.3)$ & $13.5(1.8)$ & $13.1(1.8)$ & $13.6(1.9)$ & $16.0(2.1) \S+$ \\
\hline Inspired oxygen $(\%)$ & $40(3)$ & $43(5)$ & $43(9)$ & $42(10)$ & $49(15)$ & $70(15) \S \dagger$ & $81(18) \S \div$ \\
\hline OI & $8.4(3.4)$ & $10.8(5.7)$ & $8.3(4.8)$ & $9.9(2.9)$ & $12.5(6.5)$ & $24.4(11.0) \ddagger \S$ & $27.4(12.5) \dagger \S$ \\
\hline
\end{tabular}

Data are presented as mean (SD).

Within-group comparisons:

* $P<0.05$ for 240 vs $120 \mathrm{~min}$.

$\dagger P<0.05$ for $300 v s 240 \mathrm{~min}$.

$+P<0.05$ for 360 vs $240 \mathrm{~min}$.

Between-group comparisons:

$\S P<0.05$ between two groups at given time point.

current investigation, in contrast with our previous study in which sildenafil, when given alone, did not have such an effect.

Sildenafil also produced important systemic side effects in animals that were already receiving nitric oxide when compared with controls: we observed a fall in systemic blood pressure, with hypotension and a concomitant decrease in SVR, occurring after the first $1 \mathrm{mg} / \mathrm{kg}$ of the sildenafil infusion. A similar effect on systemic blood pressure, which may be dose dependent, has been noted in other studies of oral sildenafil $(15,18)$ and other PDE-5 inhibitors $(19)$. However, we must point out that we did not observe such a significant change in systemic hemodynamics in our previous study of sildenafil alone, given at the same dose and infusion rate, to a similar group of animals. The difference that we have observed in our current study may have been due in part to the relative hypoxia with sildenafil, and beyond $300 \mathrm{~min}$, this may have been further exacerbated by the necessary increase in intrathoracic pressure.

Limitations. This study has a number of limitations. First, we did not measure intrapulmonary shunt. No animal had an intracardiac shunt to account for arterial desaturation, and we must therefore assume that the arterial hypoxemia after first meconium instillation and later during infusion of sildenafil wholly resulted from intrapulmonary shunting. Future studies should address this.

In contrast with the animals in our study, most neonates with persistent pulmonary hypertension have an intracardiac shunt at presentation; therefore, arterial hypoxemia in the presence of elevated PAPs may in part result from right-to-left shunting at the atrial or ductal level. Thus, a pharmacologic reduction in PVR may influence arterial oxygenation differently in the presence of an intracardiac shunt.
The choice of dose of iNO is another important issue. The current study was not designed to investigate the optimal dose of iNO. Thus, the dose of $20 \mathrm{ppm}$ was selected on the basis of the recommended "starting dose" of iNO in a recent metaanalysis of nitric oxide in neonatal respiratory failure (20).

The final limitation of this study was the choice of dose of sildenafil. Intravenous sildenafil is not currently used in clinical practice; its pharmacokinetics have not been investigated in children, and at the time of writing, there are no studies other than our own using the i.v. agent in piglets. Indeed, our chosen dose of sildenafil ( $2 \mathrm{mg} / \mathrm{kg}$ over $2 \mathrm{~h}$ ) was tolerated in our previous study in piglets that received sildenafil alone (12). Other groups have given $50-100 \mathrm{mg}$ enteral sildenafil as a pulmonary vasodilator to adult humans $(6,7), 0.3-2 \mathrm{mg} / \mathrm{kg}$ to children in intensive care (8, 10,11 ), and $0.6-2.6 \mathrm{mg} / \mathrm{kg}$ to healthy pigs (18). In the only report to date of i.v. sildenafil in children, $0.3-0.6 \mathrm{mg} / \mathrm{kg}$ was given over 20 min during cardiac catheterization, with "pre" and immediate "post" hemodynamic assessment (21). Finally, in a pharmacokinetic investigation of i.v. sildenafil, $0.35 \mathrm{mg} / \mathrm{kg}$ was infused over $20 \mathrm{~min}$ to healthy men and $1-4 \mathrm{mg} / \mathrm{kg}$ to various other species. Hemodynamics and oxygenation were not discussed in this study (22).

There is clearly great diversity in the dose of sildenafil used to treat pulmonary hypertension. Although this study was not intended to be a dose-finding investigation, we have shown that there was a significant deterioration in oxygenation after 0.5 $\mathrm{mg} / \mathrm{kg}$ and important systemic side effects after $1 \mathrm{mg} / \mathrm{kg}$ sildenafil. A dose-finding study of sildenafil with nitric oxide in healthy and diseased piglet lungs would be of great importance if the combination of agents is to be considered in the treatment of acute pulmonary hypertension and lung injury. 


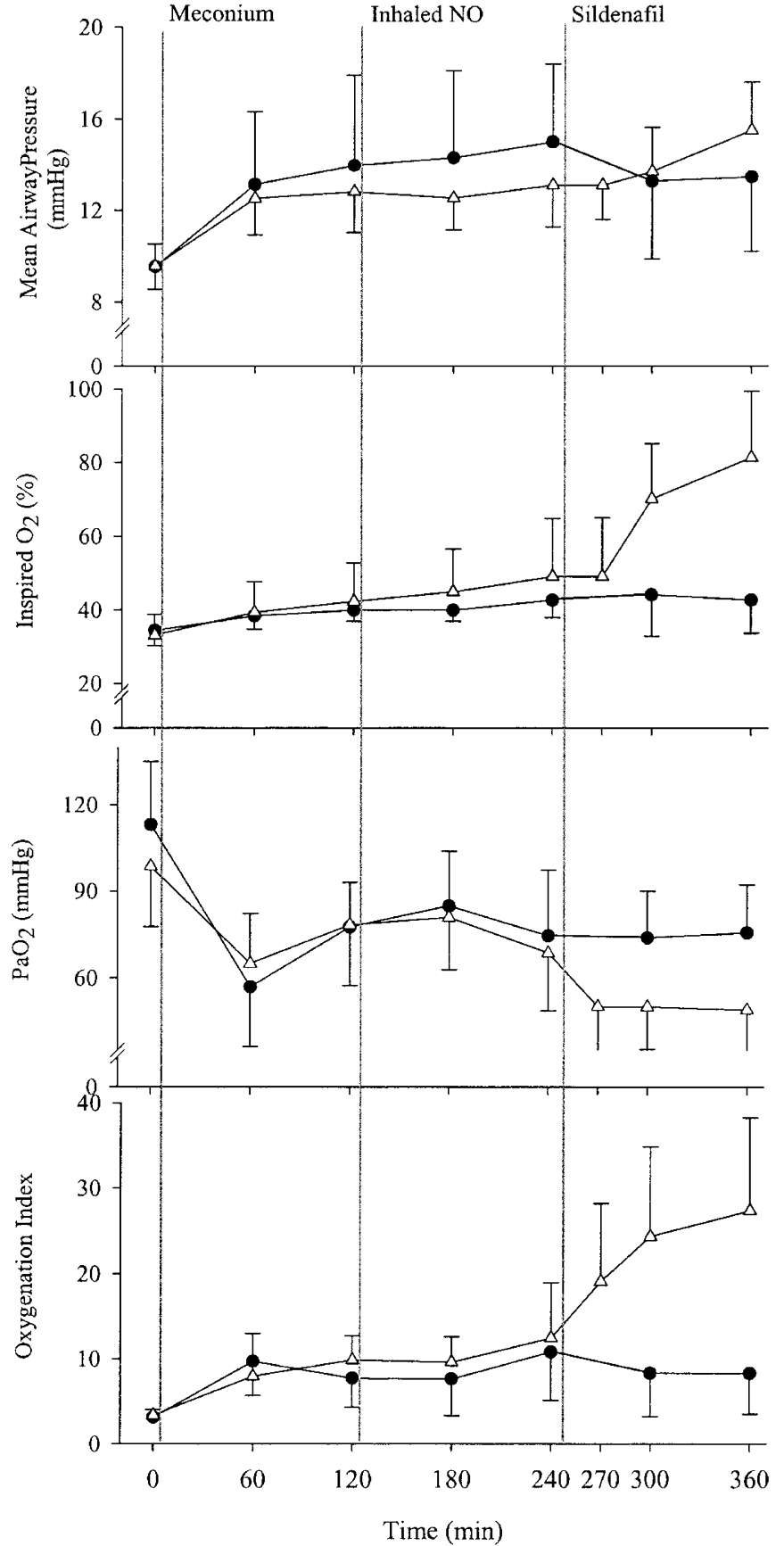

Figure 2. Changes in mean ventilatory parameters in controls $(\bullet)$ and test animals $(\triangle)$. Meconium instillation produced an reduction in arterial oxygenation and increased the ventilatory requirements of both groups. iNO alone did not influence oxygenation, but the addition of sildenafil produced sustained arterial hypoxemia, despite a substantial increase in inspired oxygen after 270 $\mathrm{min}$, and a further increase in inspired oxygen and also in mean $\mathrm{P}_{\mathrm{Aw}}$ from 300 min. Thus, OI more than doubled during sildenafil infusion.

Clinical implications. iNO was a selective pulmonary vasodilator in this model of acute pulmonary hypertension and lung injury secondary to meconium aspiration. The widespread pulmonary vasodilation and increase in cardiac output that ensued after $>0.5 \mathrm{mg} / \mathrm{kg}$ sildenafil were expressed as detrimental influences upon oxygenation and were subsequently accompanied by systemic vasodilation and hypotension. These deleterious side effects (despite an apparent reduction in PVR) would be considered unacceptable in the fragile newborn infant.

\section{CONCLUSION}

Sildenafil and iNO have complex and important interactions in this model of acute pulmonary hypertension and lung injury. The addition of i.v. sildenafil in animals that were already receiving iNO augmented the cGMP-dependent pulmonary vasodilation and resulted in systemic vasodilation and hypotension. Furthermore, the additional pulmonary vasodilation produced by sildenafil was accompanied by an increase in intrapulmonary shunt and an unacceptable deterioration in oxygenation.

\section{REFERENCES}

1. Rimensberger PC, Spahr-Schopfer I, Berner M, Jaeggi E, Kalangos A, Friedli B, Beghetti M 2001 Inhaled nitric oxide versus aerosolized iloprost in secondary pulmonary hypertension in children with congenital heart disease: vasodilator capacity and cellular mechanisms. Circulation 103:544-548

2. Clark RH, Kueser TJ, Walker MW, Southgate WM, Huckaby JL, Perez JA, Roy BJ, Keszler M, Kinsella JP 2000 Low-dose nitric oxide therapy for persistent pulmonary hypertension of the newborn. N Engl J Med 342:469-474

3. Hasuda T, Satoh T, Shimouchi A, Sakamaki F, Kyotani S, Matsumoto T, Goto Y, Nakanishi N 2000 Improvement in exercise capacity with nitric oxide inhalation in patients with precapillary pulmonary hypertension. Circulation 10:2066-2070

4. Goldman AP, Delius RE, Deanfield JE, de Leval MR, Sigston PE, Macrae DJ 1996 Nitric oxide might reduce the need for extracorporeal support in children with critical postoperative pulmonary hypertension. Ann Thorac Surg 62:750-755

5. Dukarm RC, Russell JA, Morin FC III, Perry BJ, Steinhorn RH 1999 The cGMPspecific phosphodiesterase inhibitor E4021 dilates the pulmonary circulation. Am J Respir Crit Care Med 160:858-865

6. Zhao L, Mason NA, Morrell NW, Kojonazarov B, Sadykov A, Maripov A, Mirrakhimov MM, Aldashev A, Wilkins MR 2001 Sildenafil inhibits hypoxia-induced pulmonary hypertension. Circulation 104:424-428

7. Prasad S, Wilkinson J, Gatzoulis MA 2000 Sildenafil in primary pulmonary hypertension. N Engl J Med 343:1342

8. Abrams D, Schulze-Neick I, Magee AG 2000 Sildenafil as a selective pulmonary vasodilator in childhood primary pulmonary hypertension. Heart 84:E4

9. Bigatello LM, Hess D, Dennehy KC, Medoff BD, Hurford WE 2000 Sildenafil can increase the response to inhaled nitric oxide. Anesthesiology 92:1827-1829

10. Atz AM, Lefler AK, Fairbrother DL, Uber WE, Bradley SM 2002 Sildenafil augments the effect of inhaled nitric oxide for postoperative pulmonary hypertensive crises. J Thorac Cardiovasc Surg 124:628-629

11. Atz AM, Wessel DL 1999 Sildenafil ameliorates effects of inhaled nitric oxide withdrawal. Anesthesiology 91:307-310

12. Shekerdemian LS, Ravn HB, Penny DJ 2002 Intravenous sildenafil lowers the pulmonary vascular resistance in a model of neonatal meconium aspiration. Am J Respir Crit Care Med 165:1098-1102

13. Mercier JC, Lacaze T, Storme L, Roze JC, Dinh-Xuan AT, Dehan M 1998 Diseaserelated response to inhaled nitric oxide in newborns with severe hypoxaemic respiratory failure. French Paediatric Study Group of Inhaled NO. Eur J Pediatr 157:747-752

14. Thusu KG, Morin FC 3rd, Russell JA, Steinhorn RH 1995 The cGMP phosphodiesterase inhibitor zaprinast enhances the effect of nitric oxide. Am J Respir Crit Care Med 152:1605-1610

15. Weimann J, Ullrich R, Hromi J, Fujino Y, Clark MW, Bloch KD, Zapol WM 2000 Sildenafil is a pulmonary vasodilator in awake lambs with acute pulmonary hypertension. Anesthesiology 92:1702-1712

16. Thebaud B, Saizou C, Farnoux C, Hartman JF, Mercier JC 1999 Dypiridamole, a cGMP phosphodiesterase inhibitor, transiently improves the response to inhaled nitric oxide in two newborns with congenital diaphragmatic hernia. Intensive Care Med 25:300-303

17. Adrie C, Holzmann A, Hirani WM, Zapol WM, Hurford WE 2000 Effects of intravenous Zaprinast and inhaled nitric oxide on pulmonary hemodynamics and gas exchange in an ovine model of acute respiratory distress syndrome. Anesthesiology 93:422-430

18. Kleinsasser A, Loeckinger A, Hoermann C, Puehringer F, Mutz N, Bartsch G, Lindner KH 2001 Sildenafil modulates hemodynamics and pulmonary gas exchange. Am J Respir Crit Care Med 163:339-343

19. Dukarm RC, Morin FC 3rd, Russell JA, Steinhorn RH 1998 Pulmonary and systemic effects of the phosphodiesterase inhibitor dipyridamole in newborn lambs with persistent pulmonary hypertension. Pediatr Res 44:831-837

20. Finer NN, Barrington KJ 2001 Nitric oxide for respiratory failure in infants born at or near term. Cochrane Database Syst Rev (4):CD000399

21. Schulze-Neick I, Hartenstein P, Li J, Stiller B, Nagdyman N, Hubler M, Butrous G, Petros A, Lange P, Redington AN 2003 Intravenous sildenafil is a potent pulmonary vasodilator in children with congenital heart disease. Circulation 180:II167-II173

22. Walker DK, Ackland MJ, James GC, Muirhead GJ, Rance DJ, Wastall P, Wright PA 1999 Pharmacokinetics and metabolism of sildenafil in mouse, rat, rabbit, dog and man. Xenobiotica 29:297-310 